\title{
(6) ]

\section{MODA INCLUSIVA COM FOCO EM MULHERES NO PÓS OPERATÓRIO DO CÂNCER DE MAMA}

\section{INCLUSIVE FASHION WITH FOCUS ON WOMEN POSTOPERATIVE OF BREAST CANCER}

\author{
VALÉRIO, Driélli (1); \\ MEDOLA, Fausto Orsi (2); \\ PASCHOARELLI, Luis Carlos (3)
}

(1) PPGDesign-UNESP/Bauru

E-mail: drika.valerio@hotmail.com

(2) Programa de Pós-graduação em Design, Faculdade de Arquitetura, Artes e Comunicação, UNESP-Bauru, Professor Doutor;

E-mail: fausto.medola@faac.unesp.br

(2) Programa de Pós-graduação em Design, Faculdade de Arquitetura, Artes e Comunicação, UNESP-Bauru, Professor Doutor.

E-mail: paschoarelli@faac.unesp.br

\begin{abstract}
RESUMO
Moda inclusiva tem como objetivo auxiliar pessoas com deficiência a se vestirem e despirem com mais facilidade, através de fechamentos e aberturas estratégicas em roupas. Pessoas com deficiência, idosos ou pacientes no pós operatório, apresentam dificuldade em manusear suas vestimentas, portanto se beneficiam destes produtos. Aproximadamente 50 mil novos casos/ano de mulheres com câncer de mama são detectados no Brasil. No processo da descoberta até a cura, apárte toda preocupação da mulher com sua aparência, não há estudos com foco em moda para paciente, sendo portanto objetivo deste estudo discutir as relações entre moda, design inclusivo e cirurgia de mastectomia.
\end{abstract}

Palavras-chave: Moda Inclusiva, Câncer de Mama, Tecnologia Assistiva, Design Universal.

\begin{abstract}
Inclusive fashion aims to help disabled people to dress and undress more easily through strategic closures and openings in clothes. People with disabilities, the elderly or patients after surgery, have difficulty in handling their clothing, therefore benefit from these products. Approximately 50,000 new cases / year of women with breast cancer are detected in Brazil. In the process of discovery to cure, apart all concerns of women with their appearance, there are no studies focusing on fashion for the patient. This study aims to discuss the relationship between fashion, inclusive design and mastectomy surgery.
\end{abstract}




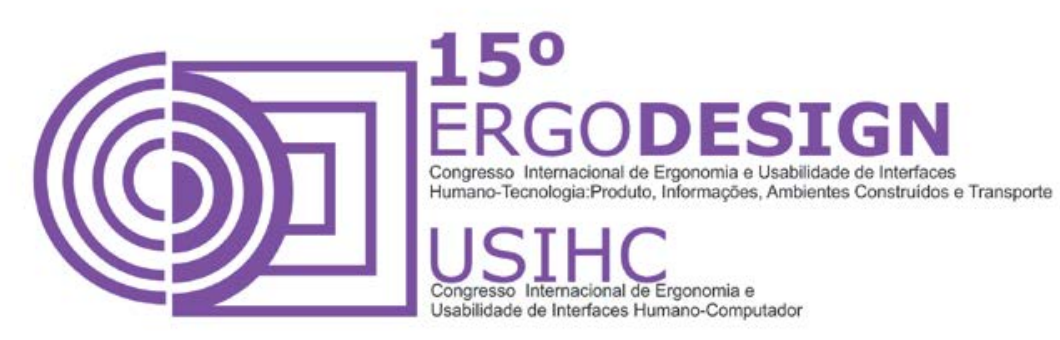

\section{INTRODUÇÃO}

Peças desenvolvidas para o público de pessoas com deficiência ou mobilidade reduzida temporária ou permanente costumam ter detalhes que facilitam a veste tanto da própria pessoa ou de cuidadores, dependendo do caso, fazendo com que a pessoa fique dependente de terceiros para vestir-se. Isto traz uma preocupação adicional, pois a mulher que, além de exposta a todos os efeitos da quimioterapia, ainda não consegue vestir sozinha uma peça de roupa que a agrade, impactando de forma importante sua auto-estima e auto-confiança que, durante o processo de tratamento, são essenciais.

Após a cirurgia, seja para retirada de um quadrante, do nódulo ou da mama completa, a paciente fica impossibilitada de realizar movimentos com os braços elevados, dificultando ainda mais a veste e o despir de qualquer tipo de roupa convencional. Diante disso, é importante estudar o design universal e a tecnologia assistiva, para poder projetar peças de roupa que sejam confortáveis, fáceis de vestir, sem deixar de lado o design e a estética da roupa.

Idealmente, as coleções deveriam ser melhor elaboradas pensando na comodidade, praticidade e facilidade na hora do usuário vesti-la, incluindo aqueles que estão temporariamente com mobilidade reduzida, no caso de pacientes no pós operatório, ou em recuperação ou tratamento, até as pessoas com deficiência, sem distinção de usuário, para que ao fazer uma compra na loja, o usuário não perceba que a peça é adaptada, podendo assim ser usada por qualquer tipo de pessoa, sem distinção de usuário.

A paciente no pós-operatório de mastectomia acaba optando por usar camisetas largas (muitas vezes do cônjuge) por ser mais prático e confortável, já que camisetas comuns com detalhes elaborados, neste período, podem ser desconfortáveis e mesmo difíceis de vestir, acarretando na perda da auto estima.

Este estudo tem como objetivo entender de que forma a moda inclusiva tem aplicação no design de todos os tipos de peças do vestuário. Busca-se contribuir com o desenvolvimento da moda inclusiva também meio hospitalar, trazendo bem estar e devolvendo a autonomia da paciente, com conforto nas peças projetadas para serem fáceis de vestir, mesmo para quem está com um braço com restrição de movimento devido à cirurgia.

\section{MODA INCLUSIVA}

O termo moda inclusiva compreende o rol de produtos de moda com o objetivo de auxiliar pessoas com deficiência e mobilidade reduzida a se vestirem e despirem com mais facilidade no dia a dia, tais como fechamentos e aberturas colocadas estrategicamente em peças de roupas que normalmente pessoas com deficiência teriam dificuldade em manusear. Atualmente, na área da moda inclusiva no Brasil, a indústria têxtil começa a se preocupar em confeccionar algo voltado para a inclusão social. Porém, o conceito de ser inclusiva muitas vezes implica em torná-la exclusiva, pelo fato de se preocupar somente com o deficiente e não com o público em geral, como deve ser idealmente democrática, abrangente e acessível. A acessibilidade do produto deve ser observada não apenas no contexto das lojas, mas também no custo, pois pouco contribui a criação de moda inclusiva com preços excessivamente altos e 


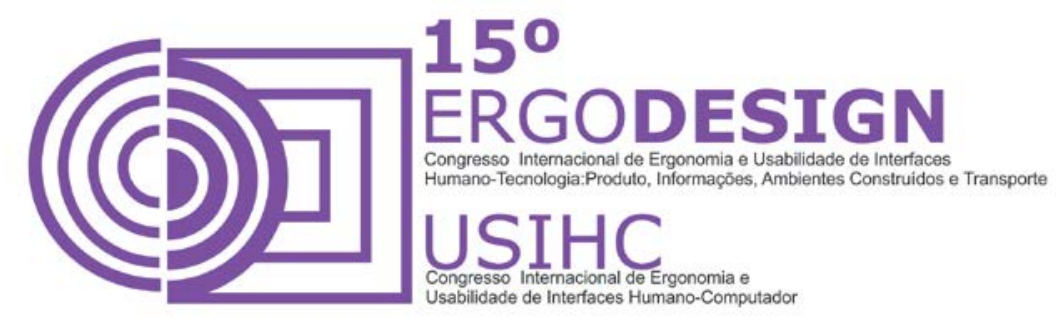

não acessíveis à maioria dos deficientes do país, que representam 45 milhões de pessoas. Tal visão encontra respaldo fala de Battistella (2014):

A moda inclusiva deve ser democrática independente do caso [...] o conceito de inclusão na moda implica em facilitar o cotidiano das pessoas com deficiência temporária ou permanente propondo soluções inovadoras e ergonômicas, seja na modelagem ou no acabamento [...] ( $\mathrm{Dr}^{\mathrm{a}}$ Linamara Battistella, médica, fisiatra, professora da faculdade de Medicina na USP e secretária de Estado dos Direitos da Pessoa com Deficiência).

Diante da necessidade de empresas voltadas para esta faixa do mercado, surgiram no Brasil algumas ONGS e concursos dispostos a incentivar a criação de moda adaptada para as pessoas com deficiência. Um deles é o evento "Moda Inclusiva", que acontece anualmente promovido pela Secretaria dos Direitos da Pessoa com Deficiência do Estado de São Paulo, que premia seus participantes com metragem de tecido, fomentando a produção na área e hoje, a indústria têxtil começa a se preocupar em confeccionar algo pensando na inclusão social

Atualmente, o mercado de vestimentas para pacientes debilitados por conta do pós operatório restringe-se principalmente aos roupões de hospital, confortáveis, mas que carecem de atributos estéticos. Isto é particularmente importante no caso de mulheres submetidas ao procedimento de mastectomia e quimioterapia, uma vez que ambos causam prejuízos importantes ao bem-estar e auto-estima da mulher. Apesar disso, ainda não existem produtos voltados a essa necessidade. Mulheres são vaidosas e nesta fase, precisam se sentir muito mais amadas e bem cuidadas. A moda inclusiva vai além das pessoas com deficiências, é para todos, sem distinção de raça, credo, deficiência ou doença.

3. CÂNCER DE MAMA NO BRASIL

O câncer de mama é o segundo mais frequente no mundo, sendo mais comum entre as mulheres, representando $22 \%$ dos novos casos no Brasil a cada ano, sendo raro antes dos 35 anos de idade. As estatisticas são alarmantes: segundo o INCA (Instituto Nacional do Câncer) em 2008 houve 11.860 mortes por cêncer de mama, sendo 11.735 mulheres e este número vem crescendo nos últimos anos.

Diante do choque emocional que é receber a notícia, pensar na possibilidade da mutilação da imagem corporal, o sentimento de auto-estima fica abalado, pois a mama representam a sexualidade, a maternidade e é um órgao de atração. Além disso, é símbolo de identidade corporal feminina, do sentimento de valor próprio e auto estima.

\begin{abstract}
O câncer de mama afeta a auto estima da mulher[...]As experiências relacionadas ao câncer são sempre negativas, podendo gerar transtornos afetivos e provocar um afunilamento do campo perceptivo, fazendo com que o paciente só veja a doença e suas consequências, reais ou fantasiosas [...] (Miceli, 2006).
\end{abstract}

Muito se fala sobre a importância da psicologia hospitalar no atendimento à mulheres com câncer, da prevenção e da queda dos cabelos, porém poucas soluções são 


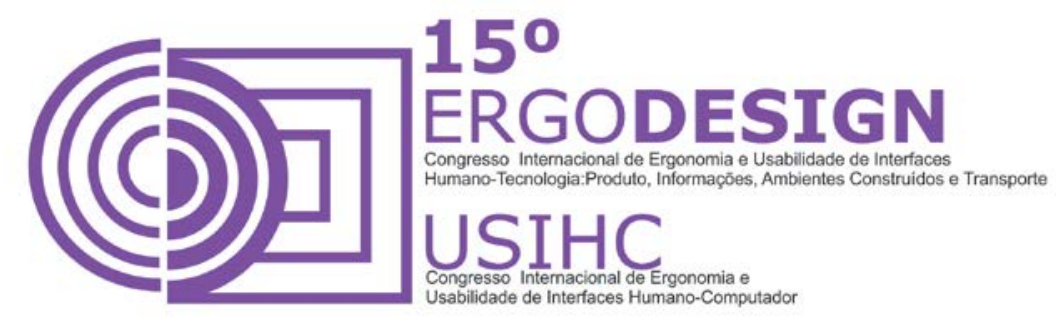

realmente oferecidas visando a auto estima da mulher que passa pelo processo da quimioterapia ou radioterapia durante o tratamento, perdendo os cabelos, com edema em regiões do corpo, assim como efeitos colaterais terríveis. Nestas situações, é difícil esperar que a mulher mantenha a auto-estima inabalada. A moda inclusiva se insere neste assunto no sentido de auxiliar na praticidade, conforto, auto estima e autonomia da mulher.

\section{DESIGN UNIVERSAL}

Design universal pode ser entendido como um instrumento através do qualconseguimos uma sociedade mais humana e igualitária para todos, tendo como objetivo a definição de projetos de produtos e ambientes para incluir toda a diversidade humana, desde criança, adultos, idosos, altos, baixos, anões, gestantes, obesos, deficientes e pessoas em geral com mobilidade reduzida, sem a necessidade de adaptações futuras..

O design universal deve abranger o maior número de pessoas possível, independente da característica física e por conta disso, está justamente aqui o nosso grande desafio: Criar uma peça do vestuário para ser universal, sem distinção, atendendo a um público grande que vai desde a pessoa com deficiência até pessoas sem nenhuma restrição de movimento, podendo qualquer pessoa utilizá-la sem distinção. A definição de Design Universal pode ser entendida como:

"O design universal deve abranger a todos [...] o propósito do Design Universal é gerar ambientes, produtos, serviços, programas e tecnologias acessíveis de forma a atender o maior número de pessoas, na maior extensão possível, sem a necessidade de adaptação ou design especializado [...]"(Centerfor Universal Design, North Caroline State University, EUA).

A principal ideia do design universal é evitar a necessidade de ambientes e produtos especiais para pessoas com deficiência, e sim pensar na inclusão na hora de projetar, tornando assim o produto ou ambiente utilizável por qualquer pessoa com segurança e autonomia. Projetar algo para ser universal não é novidade, porém dentre os projetos de produto existentes, percebemos que design universal e estética ainda são coisas distintas, tornando objetos de uso cotidiano adaptáveis e com fácil manuseio para pessoas portadoras de deficiência motora, esquecendo que o design como estética precisa estar presente também em produtos inclusivos.

Design universal remete à realidade humana e deve estar cada vez mais presente na hora de projetar tanto edificações como produtos, dispensando assim, reformas e adaptações para atender um grupo específico, criando produtos buscando atender a todos, independente de sua idade, tamanho ou condição motora.

\section{TECNOLOGIA ASSITIVA}

Termo utilizado para identificar recursos e serviços que ajudam a proporcionar ou ampliar habilidades funcionais de pessoas com deficiência, consequentemente promover a inclusão e a vida independente onde equipamentos, serviços e estratégias podem ser aplicadas para diminuir os problemas funcionais enfrentados pelo deficiente através da tecnologia assistiva, que deve ser entendida como uma ajuda que ampliará a habilidade funcional ou a realização da função desejada que se encontra impedida 


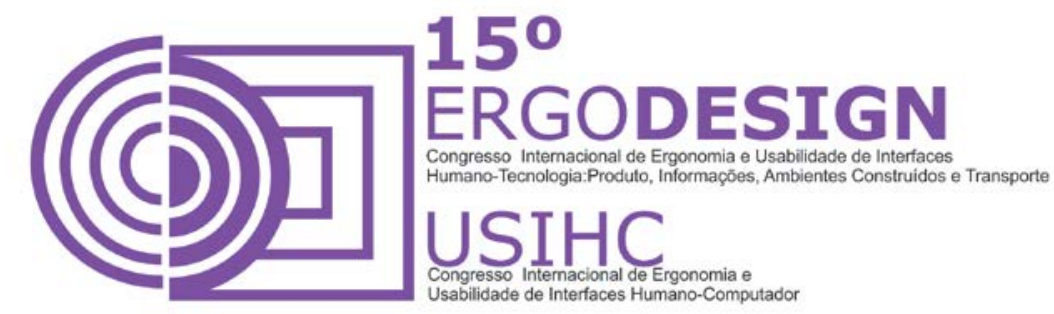

por circunstância de deficiência, como cita o trabalho "EDUCAÇÃO INCLUSIVA, DEFICIÊNCIA E CONTEXTO SOCIAL: questões contemporâneas", de da UFBA..

O objetivo da tecnologia assistiva é proporcionar à pessoa com deficiência maior independência, qualidade de vida e inclusão social, ampliando sua comunicação, mobilidade, controle, habilidade, aprendizado e trabalho, seguindo este conceito, a tecnologia aplica-se à pessoa com mobilidade reduzida, no caso do presente estudo, a paciente no pós operatório.

Introduzirmos o conceito da tecnologia assitiva com a seguinte citação [...]"Para as pessoas sem deficiência, a tecnologia torna as coisas mais fáceis.Para as pessoas com deficiência, a tecnologia torna as coisas possíveis." (RADABAUGH, 1993) [...] (Miceli, 2006).

Portanto, a tecnologia assitiva trabalha com produtos que favorecem o desempenho autônomo e independente de deficientes em tarefas do dia a dia, como alimentar-se, cozinhar, vestir-se, tomar banho e executar necessidades pessoais, aumentando assim sua auto estima.

\section{METODOLOGIA DE DESENVOLVIMENTO}

Como objetivo de desenvolver vestimenta inclusiva, tendo como suporte para a metodologia as interrelações entre design universal e a tecnologia assistiva, foi desenvolvida uma coleção de três peças para facilitar o vestir e despir de pessoas no pós-operatório de câncer de mama. O período após a cirurgia de mastectomia caracteriza-se por restrição dos movimentos do membro superior(dificultando a veste de roupas comuns), e o uso do dreno no pós operatório.

Peça 1: Camisa com botões faltos e abertura frontal total por velcro, a usuária consegue manuseá-la apenas com uma das mãos, facilitando a veste da pessoa com os movimentos restritos consequentes da cirurgia, facilitando a veste sem esforço de abotoamento e do movimento do braço.

Peça 2: Blusa frente única que amarra atrás do pescoço, pode ser vestida por cima ou por baixo, com uma pequena abertura lateral por velcro do lado da mama afetada, que possibilita regular para não apertar a cicatriz da cirurgia, e ainda por onde o dreno pode ser passado no meio do velcro que dá apoio para que o mesmo fique mais firme à mama no período de uso.

Peça 3: Blusa / bata com abertura total das alças, pode ser vestida por cima ou por baixo, confortável, amarra nos ombros possibilitando que o usuário amarre 0 comprimento de acordo com seu gosto ou necessidade.

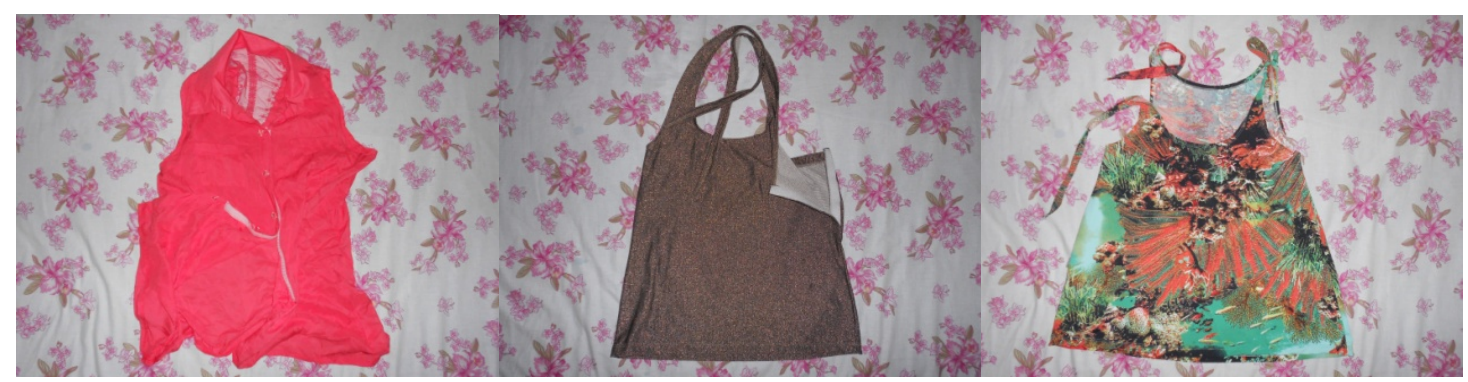

Figura 1 - Blusas adaptadas, da esquerda para a direita: Botões falsos e abertura por velcro; Abertura lateral com velcro para passagem do dreno e amarração atrás do pescoço; Veste por cima e amarra nos ombros 


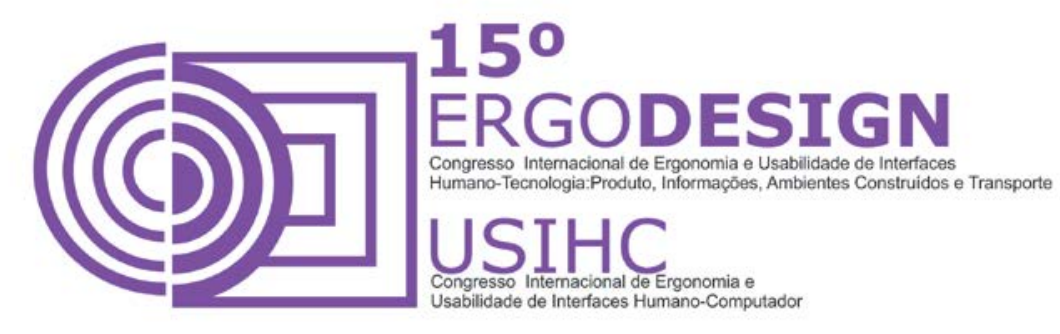

\subsection{Resultados Preliminares}

Peça 1: Blusinha / Bata estampada: Possui alças maiores para facilitar a veste por baixo, alças abertas, possibilitando que o usuário amarre o comprimento de acordo com seu gosto ou necessidade, auxiliando assim na recuperação da paciente que necessita repousar o braço após o procedimento cirúrgico, para sua melhor recuperação, não exigindo esforço para ser vestida, sendo confortável e ao mesmo tempo fashion, o que mostra que pode ser usada por mulheres o dia a dia sem nenhuma distinção.

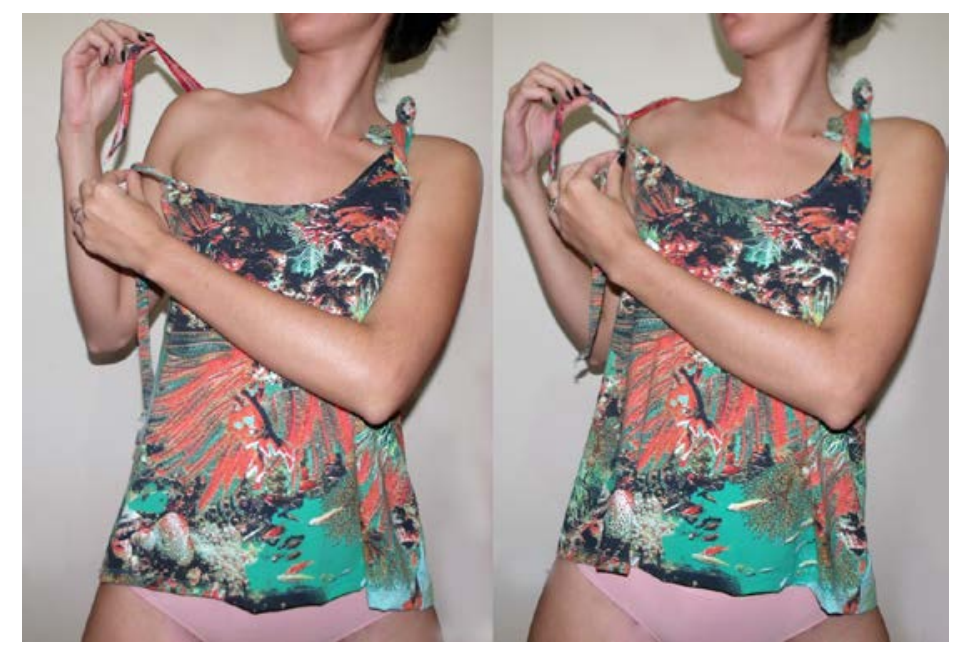

Figura 2: Peças adaptadas - Blusinha regata tipo bata estampada

Peça 2: Blusinha frente única: Com amarração atrás do pescoço, facilitando a veste por baixo ou por cima, com velcro lateral, que possibilita regulagem para não apertar a cicatriz da cirurgia e ainda, permite passar o cano do dreno no meio do velcro, de modo que segura e não atrapalha no tratamento, auxiliando no processo de cicatrização da paciente.

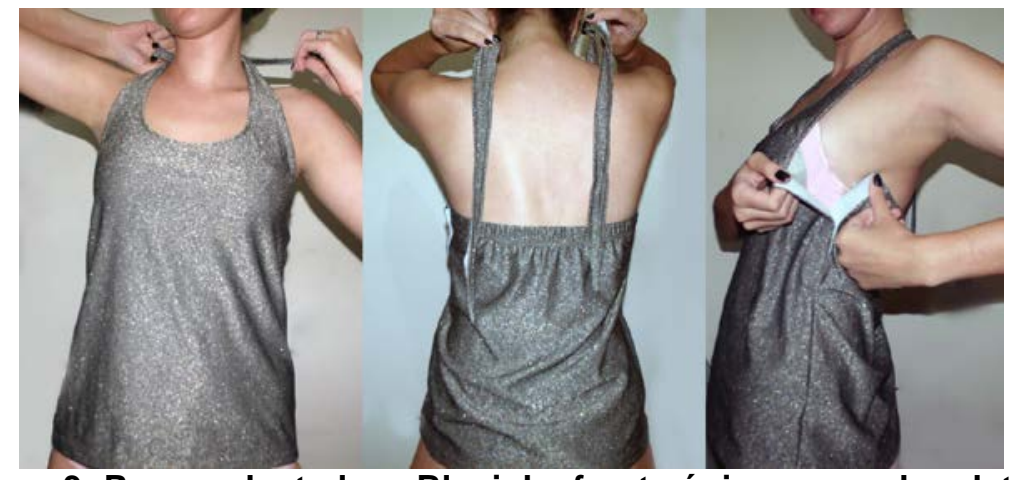

Figura 3: Peças adaptadas - Blusinha frente única com velcro lateral

Peça 3: Camisa: Sem mangas, com botões falsos apenas por estética, fechamento frontal por velcro, facilitando a veste da pessoa com os movimentos restritos consequentes da cirurgia, facilitando a veste sem esforço de abotoamento e 


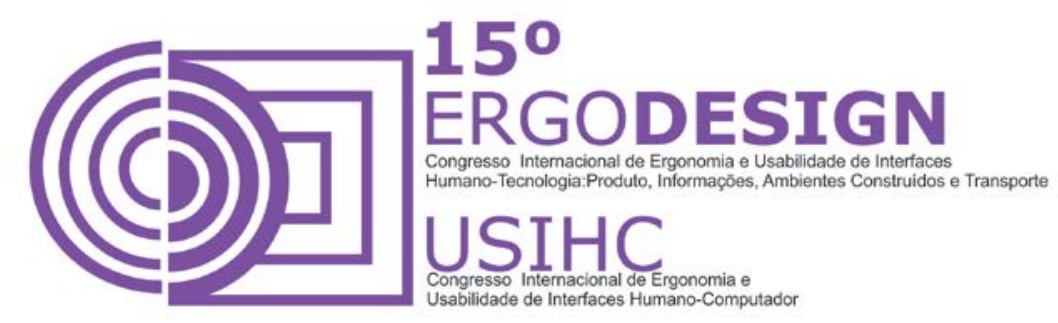

do movimento do braço, a paciente abotoa e abre a camisa de modo prático, auxiliando o repouso necessário após o procedimento cirúrgico e a sua recuperação.

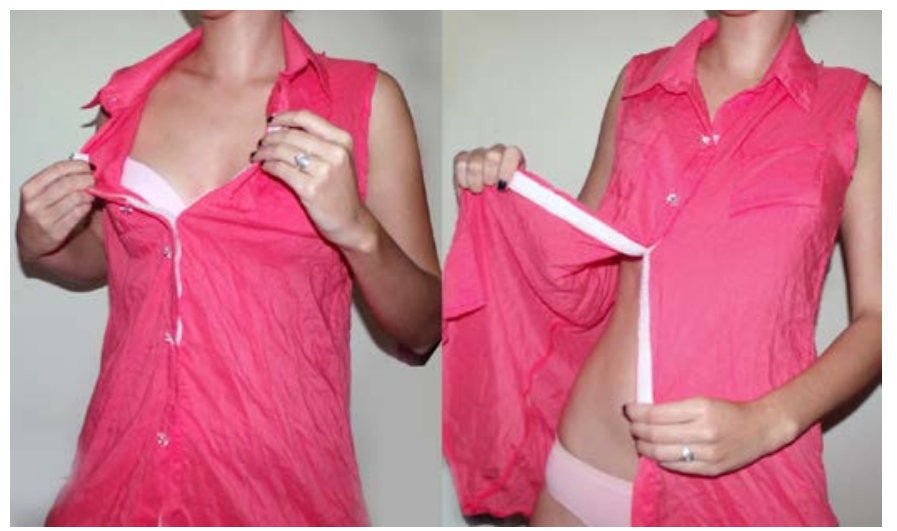

Figura 4: Peças adaptadas - Camisa com botões falsos e fechamento frontal por velcro.

\section{CONCLUSÃO}

Pacientes no pós-operatório do câncer de mama tem, além de dificuldade em vestir-se sozinha, queda da auto estima e auto confiança, o que pode atrapalhar o resultado do seu tratamento. Este estudo abordou os aspectos inclusivos do design de moda para voltado para o câncer de mama, porém abrange todos os casos de pessoas no pós operatório, incluindo idosos, crianças sem interferir no uso das peças por pessoas sem deficiência o que comprova sua eficiência, garantindo assim uma perspectiva de universalidade do uso.

As três peças de roupa apresentadas foram desenvolvidas a partir da necessidade de mulheres mastectomizadas e suas dificuldades no ato de vestir-se e todos os cuidados referentes ao processo cirúrgico e o dreno. Neste sentido, as peças buscam facilitar o ato de vestir-se, mas também não comprimir, sobrepor ou ocluir o dreno, devendo ser confortável para que facilite a recuperação do paciente. Assim, espera-se que, unindo o design ao estilo, as pacientes melhorem a auto estima que, normalmente, está debilitada psicologicamente.

As contribuições do estudo dizem respeito aos seguintes resultados: valor: peça adaptada (inclusiva) mantendo a auto estima do paciente; vantagem: praticidade e independência do usuário na hora de vestir / despir; utilidade: vestir pacientes de câncer de mama no pós operatório, preservando a estética e as tendências de moda durante o tratamento; benefício: fácil de vestir, confortável, facilitando a circulação e a cicatrização. Novos estudos devem avaliar a influência destes produtos na funcionalidade, conforto, satisfação e auto estima das mulheres submetidas ao procedimento de mastectomia.

\section{REFERÊNCIAS BIBLIOGRÁFICAS}

ABNT. NBR 9050: 2004 Acessibilidade de pessoas portadoras de deficiências a edificações,

BAUDOT, François. Moda do século. São Paulo: Cosac Naify, 2002. 


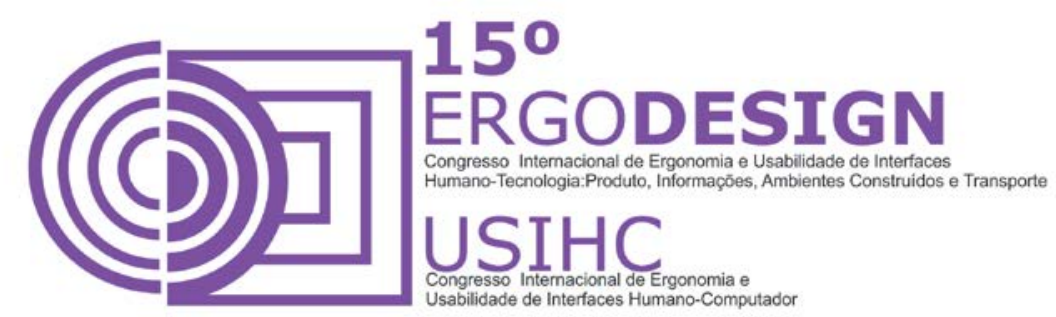

BERSCHI, Rita. Introdução à Tecnologia Assistiva, Porto Alegre, 2008.

BRASIL. Ministério de Ciência e Tecnologia. Seleção pública de propostas para apoio a projetos de pesquisa e desenvolvimento de tecnologias assistivas para inclusão social de pessoas portadoras de deficiência e de idosos. Brasília, setembro 2005. Disponível em: <http://www.mct.gov.br/index.php/content/view/10253.html> Acesso em 08 dez, 2014.

BRASIL. Portal de Ajudas Técnicas.. Disponível em: $<$ http://portal.mec.gov.br/seesp/index.php?option=content\&task=view\&id=64\&ltemid=193> Acesso em $08 \mathrm{dez}, 2014$.

BRASIL. Tecnologia Assistiva. Disponível em: <http://www.assistiva.org.br/> Acesso em 09 dez, 2014.

CARLETTO; Ana Claudia; CAMBIAGHI, Silvana. Desenho Universal: Um conceito

DONDIS, Donis A. Sintaxe da Linguagem Visual . São Paulo: Martins Fontes, 2007.

DIAS, Félix, EDUCAÇÃo INCLUSIVA, DEFICIÊNCIA E CONTEXTO SOCIAL: questões contemporâneas. Disponível em: https://repositorio.ufba.br/ri/bitstream/ufba/170/1/Educacao\%20Inclusiva.pdf, acesso em 10 de janeiro de 2015

FILHO, João G. Gestalt do objeto - Sistema de leitura visual da forma. São Paulo: Escrituras, 2000.

Gebrim, LH, Quadros LGA. Rastreamento do câncer de mama no Brasil. Rev Bras Ginecol Obstet [Internet]. 2006 28(6):319-323. Disponível em: http://www.scielo.br/scielo.php?pid=S0100$72032006000600001 \&$ script=sci_arttextacesso em 5 de outubro de 2014

GRAVE, Maria de Fátima. A Modelagem sob a ótica da ergonomia. São Paulo: Zennex, 2004.

GRAVE, Maria de Fátima. A Moda-vestuário ergonomia do Hemiplégico. São Paulo: Escrituras, 2010.

GRAVE, Maria de Fátima. Modelagem Tridimensional Ergonômica. São Paulo: Escrituras, 2010.

KALIL, Glória. Chic[érrimo] Moda e etiqueta em novo regime. São Paulo: Codex, 2004.

LEITE, Adriana Sampaio. VELLOSO, Marta Delgado. Desenho técnico de roupa feminina. Rio de Janeiro: Senac Nacional, 2007.

LUPTON, Ellen. Novos fundamentos do design. São Paulo: Cosac Naify, 2008.

MAFFEI, Simone. Antropometria no design de moda: da representação bidimensional ao uso tridimensional. Disponível em: <http://www.educacaografica.inf.br/artigos/a-antropometria-nodesign-de-moda-da-representacao-bidimensional-ao-uso-tridimensional> Acesso em 16 fev, 2012.

MICHELINE, Marcos. Avaliação e análise de acessibilidade de um deficiente físico motor, através do software Catia, em habitações de interesse social. Curitiba, 2005.

MORAES, Patrícia. Deficiências Motoras. (s.l.) 2012. Disponível em: 


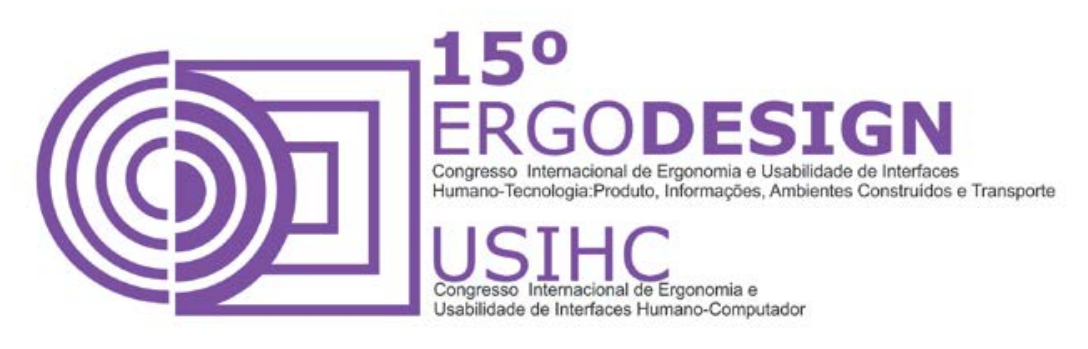

<http://www.trabalhosfeitos.com/ensaios/Deficiencia-Motora/175688.html.> Acesso em 15 dez, 2014.

Ministério da Saúde. Instituto Nacional de Câncer (INCA). Estimativa 2010: incidência de câncer no Brasil. Rio de Janeiro: INCA; 2009 [acesso em 5 out 2011]. Disponível em: http://www.inca.gov.br/estimativa/2010/estimativa20091201.pdf

MUNARI, Bruno. Das Coisas Nascem Coisas. Lisboa: Edições 70, 1981.

O’HARA, Georgina. Enciclopédia da moda. São Paulo: Companhia das letras, 1992.

Oliveira EX, Melo EC, Pinheiro RS, Noranha CP, Carvalho MS. Acesso à assistência oncológica: mapeamento dos fluxos origem-destino das internações e dos atendimentos ambulatoriais. O caso do câncer de mama. Cad Saude Publica. 2011 Feb;27(2):317-26.

para todos, 2008. Disponível em: <http://www.maragabrilli.com.br/desenho- universal.html>. Acesso em 07 dez, 2014.

PEQUINI, Suzi Mariño. Aplicação de Antropometria no Design de Produtos. SP

SANTOS, Raquel. Antropometria. Universidade de Évora - Curso Pós Graduação: Técnico $\begin{array}{llll}\text { Superior de HST. } & 2003 . & \text { Disponível } & \text { em:< }\end{array}$ http://www.histeo.dec.ufms.br/materiais/projetodeinteriores/04\%20-\%20Antropometria\%20-

\%20Raquel\%20Santos\%20e\%20Carlos\%20Fujao.pdf> Acesso em 17 dez, 2014.

São Paulo, 2005 FAU/USP. Disponível em: $<$ www.posdesign.com.br/...suzi/.../12\%20Capítulo\%208\%20-

\%20Aplicação\%20da\%20antropometria.pdf>. Acesso em: 01 dez, 2014.

SEIVEWRIGHT, Simon. Fundamentos de design de moda: Pesquisa e design. Porto Alegre: Bookman, 2009.

SENAC. Dn. Modelagem plena feminina. Rio de Janeiro: Senac Nacional, 2008.

SIMÕES, Jorge Falcato. Design Inclusivo, Acessibilidade e Usabilidade em Produtos, Serviços e Ambientes. Lisboa: CTP Produções, 2006.

WONG, Wucius. Princípios de forma e desenho. São Paulo: Martins Fontes, 1998. 